20

\title{
Оптическое просветление кожи человека in vivo рядом моносахаридов
}

\author{
(C) К.В. Березин ${ }^{1}$, К.Н. Дворецкий ${ }^{2, \uparrow, ~ М . Л . ~ Ч е р н а в и н а ~}{ }^{1}$, В.В. Нечаев ${ }^{3}$, А.М. Лихтер ${ }^{4}$, И.Т. Шагаутдинова ${ }^{4}$, \\ Е.М. Антонова ${ }^{5}$, В.В. Тучин ${ }^{1,6,7}$
}

${ }^{1}$ Саратовский национальный исследовательский государственный университет,

410012 Саратов, Россия

${ }^{2}$ Саратовский государственный медицинский университет,

410012 Саратов, Россия

${ }^{3}$ Саратовский государственный технический университет,

410054 Саратов, Россия

${ }^{4}$ Астраханский государственный университет,

414056 Астрахань, Россия

${ }^{5}$ Астраханский государственный медицинский университет,

414000 Астрахань, Россия

${ }^{6}$ Институт проблем точной механики и управления РАН,

410028 Саратов, Россия

${ }^{7}$ Национальный исследовательский томский государственный университет,

634050 Томск, Россия

ฯe-mail: dcn@yandex.ru

Поступила в редакцию 18.01.2019 г.

В окончательной редакции 18.01.2019 г.

Принята к публикации 22.02.2019 г.

С помощью метода оптической когерентной томографии (ОКТ) получены результаты оптического иммерсионного просветления кожи человека in vivo рядом водных растворов иммерсионных агентов (моносахаров рибозы, глюкоза и фруктозы, а также трехатомного спирта - глицерола). Для оценки эффективности оптического просветления определялись значения скорости изменения коэффициента рассеяния света, полученные с помощью усредненного А-скана ОКТ-сигнала на участке дермы глубиной от 350 до $700 \mu \mathrm{m}$. Установлена хорошая корреляция между скоростью изменения коэффициента рассеяния света и потенциалом оптического просветления. В результате комплексного молекулярного моделирования методами классической молекулярной динамикой и квантовой химии взаимодействия ряда иммерсионных просветляющих агентов с миметическим пептидом коллагена (GPH) з установлены корреляции между эффективностью оптического просветления и энергией межмолекулярного взаимодействия просветляющих агентов с фрагментом пептида коллагена.

Ключевые слова: оптическое просветление, моносахара, коэффициент расеяния.

DOI: $10.21883 /$ OS.2019.08.48051.29-19

\section{Введение}

Использование современных методов фотомедицины и биомедицинской оптики для диагностики и терапии заболеваний сопряжено с трудностями, которые возникают из-за того, что кожа и многие другие биоткани обладают сильным рассеянием света в видимой и ближней инфракрасной областях. Это рассеяние возникает за счет неоднородностей показателей преломления на границах различных макромолекулярных структур, в основном на коллагеновых волокнах, которые преимущественно ответственны за рассеяние света в коже [1]. Эти трудности преодолеваются путем введения в ткань биосовместимых молекулярных агентов, которые в той или иной степени способствуют ее оптическому просветлению [2-5]. Экспериментальным in vivo и in vitro исследованиям просветления различных типов биотканей посвящено довольно много работ [6-12], что говорит об актуальности проблемы. В работе [13] методами оптическая когерентной томографии (ОКТ) оценено синергетическое действие иммерсионного агента (ПЭГ-400), двух химических усилителей проникновения (триазина и 1,2-пропандиола) и физического массажа на эффективность оптического просветления кожи крысы in vivo. В работе [14] предложена математическая модель распространения света в биотканях. Разработка технологии неинвазивного определения локальной молекулярной диффузии иммерсионных агентов, основанная на ОКТ, описана в [15]. В работе [16] рассмотрено влияние модельного сахарного диабета на оптическое просветления кожи лабораторных мышей. В работе [17] путем визуализации с помощью второй оптической гармоники (SHG-imaging) исследовался механизм оптического просветления кожи при использовании глицерина в качестве просветляющего агента. Тем не менее, 
механизмы оптического просветления на молекулярном уровне до сих пор однозначно не определены, а изучению молекулярных процессов, ответственных за оптическое просветление кожи, посвящены единичные работы $[1,18,19]$. В работе [20] представлены результаты исследований дегидратирующих свойств просветляющих агентов и отмечается, что дегидратация - это только один из возможных механизмов, приводящих к просветлению биотканей. Проведение исследований в этой области открывает путь к пониманию сути процессов оптического просветления на молекулярном уровне, что в свою очередь позволит применять новые эффективные просветляющие агенты с заданными свойствами.

Настоящая работа является продолжением изучения авторами молекулярного механизма оптического просветления биотканей. В работах $[21,22]$ методом классической молекулярной динамики проведено исследование взаимодействия иммерсионного агента глицерина с миметическим пептидом коллагена $\left((\mathrm{GPH})_{9}\right)_{3}$ и фрагментом микрофибриллы $5\left((\mathrm{GPH})_{12}\right)_{3}$. Проанализировано изменение геометрических параметров $\alpha$-цепей коллагена при различных концентрациях водного раствора глицерина. Показано, что эти изменения нелинейно зависят от концентрации и имеют максимум, что хорошо коррелирует с экспериментальными данными по эффективности оптического просветления кожи человека. Высказано предположение о причине снижения эффективности оптического просветления кожи при высоких концентрациях иммерсионного агента.

В работах [23-25] методами классической молекулярной динамики, молекулярного докинга и квантовой химии (РM6 и DFT/B3LYP) проведены исследования взаимодействия шести просветляющих биологические ткани иммерсионных агентов (1,2 и 1,3-пропандиол, этиленгликоль, глицерол, ксилитол и сорбитол) с миметическими пептидом коллагена $(\mathrm{GPH})_{3}$. Установлены корреляции между потенциалом оптического просветления и такими параметрами межмолекулярных взаимодействий, как время нахождения агентов в водородосвязанном состоянии, относительная вероятность образования двойных водородных связей и энергия образования комплексов. Используя установленную корреляцию, предсказано численное значение потенциала оптического просветления молекулы декстрозы для кожи крысы, которое хорошо согласуется с экспериментальными данными. Дано объяснение незначительного изменения потенциала оптического просветления при переходе от моносахаридов к дисахаридам. Предложен молекулярный механизм последиффузинной стадии оптического просветления биотканей.

В рамках настоящей работы проводится дальнейшее изучение корреляции эффективности оптического просветления биологической ткани и энергией образования комплексов между просветляющими иммерсионными агентами с миметическими пептидом коллагена. В качестве иммерсионных агентов использовались ряд моносахаров: рибоза, глюкоза и фруктоза.

\section{Методика и результаты эксперимента}

Для исследования оптического просветления кожи в работе использовались водные растворы (60\%) следующих иммерсионных агентов: моносахаров (рибоза, глюкоза и фруктоза), а также для сравнения трехатомный спирт - глицерол. Оптическая когерентная томография использовалась для оценки влияния просветляющих свойств иммерсионных жидкостей на кожу в экспериментах in vivo. Визуализация проводилась с помощью оптического когерентного томографа Thorlabs OCP930SR (Thorlabs, CША) со следующими параметрами: центральная длина волны излучения $930 \pm 5 \mathrm{~nm}$, аксиальное и латеральное разрешение 6.2 и $9.6 \mu \mathrm{m}$ соответственно (на воздухе), длина области сканирования $2 \mathrm{~mm}$.

Для проведения исследования оптического просветления кожи человека in vivo было получено разрешение этической комиссии Саратовского государственного медицинского университета. Измерения проводились на участке кожи с внутренней стороны предплечья. Запись сканов с исследуемой области проводилась до воздействия иммерсионных агентов, затем с интервалом в $1 \mathrm{~min}$ во время действия агентов на протяжении $40 \mathrm{~min}$. В измерениях участвовало 4 добровольца, было проведено по 5 экспериментов для каждого иммерсионного агента.

На основе модели однократного рассеяния [26,27] по наклону ОКТ-сканов оценивался коэффициент ослабления $\mu_{t}$ [28]. В соответствии с моделью однократного рассеяния мощность регистрируемого ОКТ-сигнала $R(z)$ пропорциональна $\exp \left(-\mu_{t} z\right)$ [29]. Поскольку в исследуемом спектральном диапазоне коэффициент поглощения $\mu_{a}$ кожи много меньше коэффициента рассеяния $\mu_{s}$ [1], то коэффициент ослабления $\mu_{t}=\mu_{s}+\mu_{a}$ можно считать приблизительно равным коэффициенту рассеяния. Поэтому величина $R(z)$ может быть аппроксимирована следующим выражением:

$$
R(z)=A \exp \left(-\mu_{s} z\right)+B
$$

где $A-$ коэффициент пропорциональности, равный $P_{0} a(z) ; P_{0}$ - оптическая мощность в пучке, падающем на поверхность биоткани; $a(z)$ определяется локальной способностью биоткани рассеивать свет назад, которая зависит от локальной вариации показателя преломления; $B$ - фоновый сигнал. Подбор коэффициентов в приведенном выше выражении для аппроксимации экспериментальной кривой позволяет оценить усредненный по глубине (эффективный) коэффициент рассеяния света образцом ткани.

На рис. 1 представлены анализируемые области ОКТизображения, усредненный А-скан ОКТ-сигнала дермального слоя кожи человека in vivo (через $5 \mathrm{~min}$ после нанесения на поверхность 60\%-раствора рибозы) и аппроксимирующая кривая, построенная с использованием 


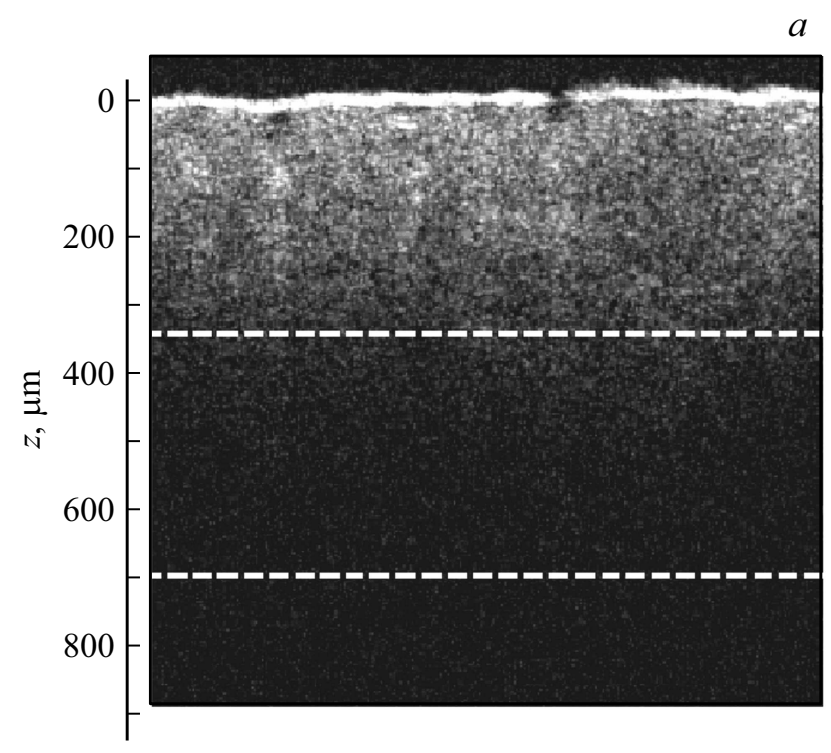

$a$

$b$

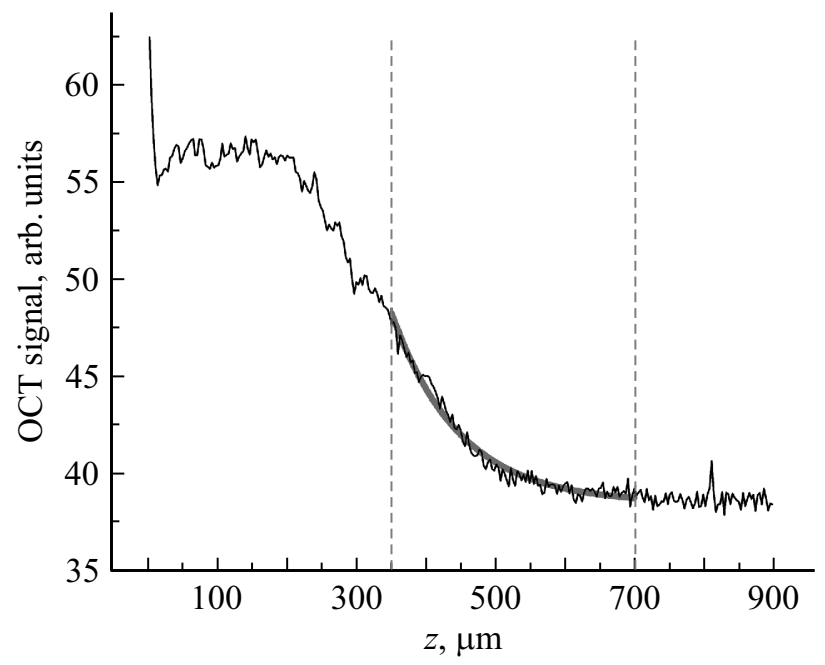

Рис. 1. Измерения коэффициента рассеяния $\mu_{s}$ на участке дермы с глубиной от 350 до $700 \mu$ m на основе анализа распределения усредненного ОКТ-сигнала по глубине с помощью модели однократного рассеяния: $a$ - фрагмент В-скана кожи in vivo, по которому проводилось усреднение ОКТ-сигнала; $b$ - распределение усредненного ОКТ-сигнала по глубине (тонкая кривая) и результат аппроксимации согласно модели однократного рассеяния (толстая кривая). Штриховыми прямыми обозначены границы участка, на котором оценивалось значение $\mu_{s}$.

модели однократного рассеяния. ОКТ-сигналы усреднялись по А-скану на всей области сканирования. Значения коэффициента рассеяния определялись на участке усредненного А-скана на глубине от 350 до $700 \mu \mathrm{m}$.

В рамках данной работы для оценки эффективности оптического просветления кожи человека in vivo определялись значения коэффициента рассеяния света, полученные с помощью усредненного А-скана ОКТ на участке дермы глубиной от 350 до $700 \mu \mathrm{m}$. Временные зависимости полученных коэффициентов рассеяния света при воздействии на кожу водных 60\%-растворов трех моносахаров и трехатомного спирта глицерола представлены на рис. 2. Из рисунка видно, что скорость просветления на большом временном интервале носит нелинейный характер и хорошо описывается экспоненциальной регрессионной моделью (коэффициент детерминации $R^{2}$ лежит в интервале от 60 до 90\%). Однако на небольшом временном отрезке эта зависимость может хорошо описываться и в рамках более простой линейной регрессионной модели. Для выбранного в данной работе участка дермы оптимальным оказался временной интервал от 7 до $24 \mathrm{~min}$. Коэффициент детерминации $R^{2}$ для линейной регрессионной модели лежит в диапазоне от 50 до 80\%, что делает эту модель приемлемой для описания полученной зависимости.

В качестве численного выражения эффективности оптического просветления кожи были использованы значения модуля средней скорости изменения коэффициента рассеяния на выбранном временном отрезке. Эти скоро- сти представлены на графиках в виде коэффициента при переменной $x$ в уравнениях регрессии.

\section{Методика и результаты молекулярного моделирования}

В качестве молекулярной модели коллагена, как и в предыдущих работах [21-25], был использован миметический пептид коллагена $(\mathrm{GPH})_{3}[30]$, составляющего основу большей части регулярных доменов коллагена человека. Такие относительно небольшие синтетические пептиды часто используются для молекулярного моделирования коллагенов. Трехмерная модель пептида строилась по данным из Protein Data Bank (PDB) с последующим добавлением атомов водорода и оптимизации структуры методом молекулярной динамики [31]. В качестве иммерсионных просветляющих агентов нами были рассмотрены ряд моносахаров (рибоза, глюкоза и фруктоза). Молекулярное моделирование взаимодействия просветляющих агентов с коллагеном проводилось в два этапа.

Ha первом этапе методом DFT/B3LYP/6-311+ $+\mathrm{G}(\mathrm{d}, \mathrm{p}) \quad[32,33]$ с использованием программы Gaussian [34] были определены и рассчитаны все самые низкоэнергетические конформеры рассматриваемых сахаров в изолированном состоянии. Вычисленные геометрические параметры и значения зарядов на атомах по Малликену в дальнейшем использовались при моделировании этих систем в рамках классической молекулярной динамики. Также были вычислены и 

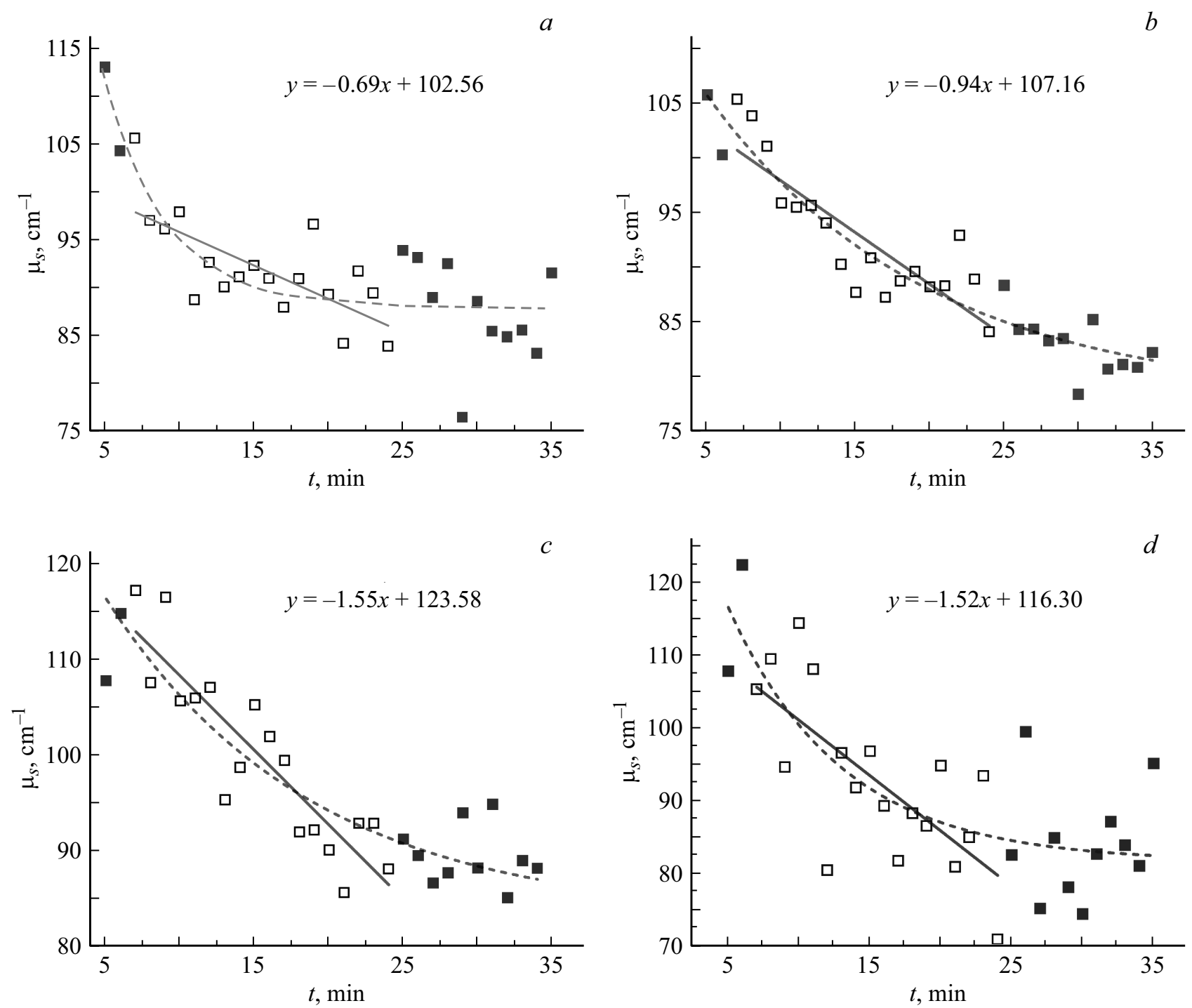

Рис. 2. Зависимость коэффициента рассеяния $\mu_{s}$ от времени действия иммерсионных агентов глицерола $(a)$, рибозы $(b)$, глюкозы $(c)$, фруктозы $(d)$ на участке дермы с глубиной от 350 до $700 \mu \mathrm{m}$ на основе анализа распределения усредненного ОКТ-сигнала по глубине с помощью модели однократного рассеяния. Экспоненциальная аппроксимации этой зависимости изображена штриховой линией. Сплошной линией изображена линейная аппроксимация на временном отрезке от 7 до 24 min (эти аппроксимируемые данные представлены светлыми квадратами).

волновые числа колебательных переходов, которые оказались положительными, что дополнительно свидетельствует о нахождении молекулярных систем в локальных минимумах. Пространственные конфигурации наиболее низкоэнергетических конформеров некоторых просветляющих агентов показаны на рис. $3, a, b$.

На втором этапе для оценки энергии межмолекулярного взаимодействия выбранных просветляющих агентов с коллагеном был использован минимальный фрагмент миметического пептида, сохраняющий регулярную структуру - $\left((\mathrm{GPH})_{3}\right)_{2}$, состоящий из 231 атома, структура которого предварительно оптимизировалась в рамках полуэмпирического метода РМ6 [35]. Полученная пространственная структура показана на рис. 3,c. Как видно из рис. 3,c, посадочный молекулярный карман представляет собой участок пептида размером приблизительно 10 на $12 \AA$, в котором имеются четыре доступные для межмолекулярного связывания функциональные группы: две карбонильные (одна (2) - на остатке глицина, другая (3) - на остатке гидроксипролина одной и тоже $\alpha$-цепи) и две спиртовые $(1,4)$ - на остатках гидроксипролинов различных $\alpha$-цепей. Эта оптимизированная структура модели коллагена использовалась для проведения молекулярного докинга с просветляющими агентами по программые AutoDockVina [36].

После проведения молекулярного докинга для каждой взаимодействующей системы выбирались первые пять наиболее выгодных конфигураций, которые далее оптимизировались полуэмпирическим методом РМ6. Затем путем проведения однократной SCF-процедуры методом 


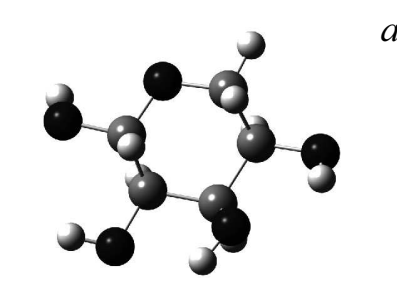

$a$

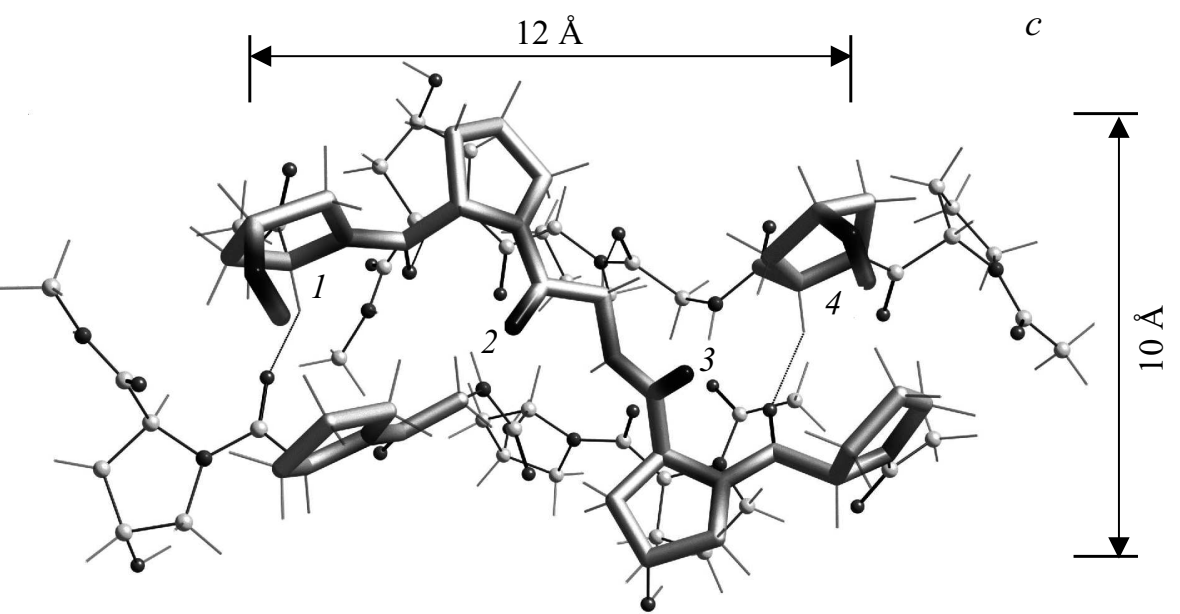

$d$
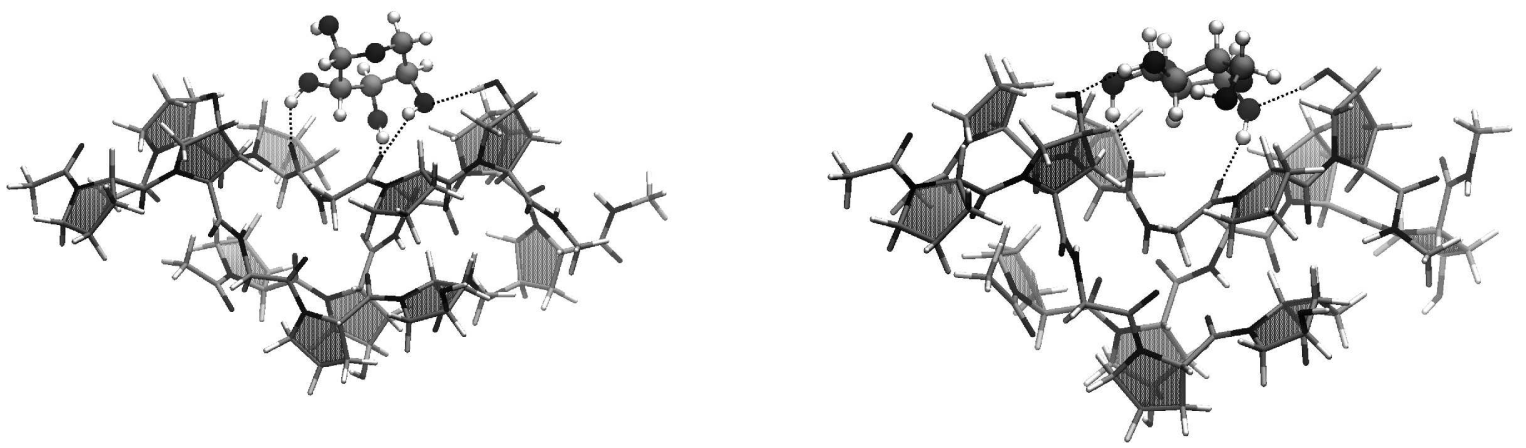

Рис. 3. Пространственные конфигурации $(a, b)$ самых низкоэнергетических конформеров некоторых просветляющих агентов (рибозы и глюкозы); $c$ - фрагмента миметического пептида $\left((\mathrm{GPH})_{3}\right)_{2}$, оптимизирована полуэмпирическим методом РМ6 (цифрами обозначены молекулярные группы, участвующие в образовании водородных связей с просветляющими агентами); $d, e$ - водородосвязанных комплексов, образованных фрагментом коллагена $\left((\mathrm{GPH})_{3}\right)_{2}$ и указанными выше иммерсионными просветляющими агентами. Пунктирными линиями на рисунке показаны водородные связи.

Длины водородных связей, энергии межмолекулярных взаимодействий между фрагментом коллагена (GPH) 3 и различными просветляющими агентами, рассчитанные методом PM6/B3LYP/6-31G(d), а также экспериментальные значения скорости оптического просветления и их стандартные ошибки

\begin{tabular}{l|l|c|c}
\hline Тип агента & Длины водородных связей, $\AA$ & $\Delta E, \mathrm{~kJ} / \mathrm{M}$ & $\begin{array}{c}\text { Эффективность оптического } \\
\text { просветления кожи }\end{array}$ \\
\hline Глицерол & $1.74,1.91,1.92,1.93,2.44$ & -42.8 & $0.69( \pm 24.6 \%)$ \\
Рибоза & $1.84,1.90,1.91,1.95$ & -80.9 & $0.94( \pm 16.0 \%)$ \\
Глюкоза & $1.68,1.71,1.84,1.94$ & -94.5 & $1.55( \pm 12.9 \%)$ \\
Фруктоза & $1.82,1.84,1.90,1.96,2.23$ & -89.2 & $1.52( \pm 24.3 \%)$
\end{tabular}

DFT/B3LYP/6 - 31G(d) вычислялись полная электронная энергия комплексов. Аналогичная процедура была использована для получения значений полной электронной энергии просветляющих агентов и пептидного фрагмента. Энергия межмолекулярного взаимодействия рассчитывалась, как разность полных энергий комплекса и суммы энергий отдельных его составляющих. Для установления корреляции с эффективностью оптического просветления были выбраны наибольшие значения энергий межмолекулярного взаимодействия, соответствующие наиболее вероятным структурам комплексов.
На рис. 3, d,e показано полученное в рамках метода РМ6 пространственное строение водородосвязанных комплексов, образованных фрагментами коллагена $\left((\mathrm{GPH})_{3}\right)_{2}$ и некоторыми просветляющими агентами.

\section{Обсуждение и выводы}

Для удобства обсуждения полученных результатов в таблице сведены количественные параметры межмолекулярных взаимодействий (значения длин классических водородных связей, образованных согласно расчету меж- 
ду активными группами молекулярного кармана коллагена и гидроксильными группами просветляющих агентов, и вычисленные значения энергий межмолекулярных взаимодействий), а также экспериментально полученные с помощью ОКТ значения модуля средней скорости изменения коэффициента рассеяния.

Например, как видно из таблицы, молекула трехатомного спирта глицерола образует четыре относительно сильные водородные связи и одну более слабую со всеми активными группами посадочного кармана, однако общей длины молекулы недостаточно, чтобы все водородные связи были максимально эффективными. При переходе от трехатомного спирта глицерола к моносахариду глюкозе наблюдается значительное увеличение эффективности оптического просветления кожи. Это можно объяснить тем, что глюкоза согласно расчету образует более сильные водородные связи с коллагеном, чем глицерол. Из таблицы видно, что несмотря на меньшее количество образованных водородных связей, их длина заметно короче, что и является определяющим фактором для энергии связывания. Как видно из рис. 3, $е$, более сильные водородные связи с карбонильными группами образуются как за счет компактной кольцевой структуры глюкозы, которая позволяет ей достаточно низко опуститься в молекулярный карман коллагена, так и за счет хорошего взаимного расположения взаимодействующих групп.

Для оценки степени (эффективности) оптического просветления иммерсионными агентами разными авторами используются различные параметры. Так, например, в [1] для этого используется потенциал оптического просветления, который вводится как коэффициент наклона зависимости приведенного коэффициента рассеяния после $45 \mathrm{~min}$ действия иммерсионного агента от его концентрации, выраженной в молях. То есть, для его определения требуется исследовать действие иммерсионных агентов с различными начальными концентрациями.

В рамках данной работы в качестве численного выражения эффективности оптического просветления кожи были использованы значения модуля средней скорости изменения коэффициента рассеяния при воздействии водного раствора иммерсионного агента средней концентрации (60\%). Из рис. 4 видно, что оба этих параметра хорошо коррелируют между собой. Это позволяет нам использовать в дальнейших исследованиях значение скорости просветления как способ оценки эффективности оптического просветления иммерсионными агентами.

Также из рис. 4 видно, что рассчитанные методом PM6/B3LYP/6-31G энергии взаимодействия молекулы пептида коллагена с молекулами различных просветляющих агентов (значения для спиртов взяты из [23]) хорошо коррелируют как с величиной потенциала оптического просветления кожи крысы и человека [1], так и с экспериментально полученными в рамках данной работы значениями скорости изменения коэффициента рассеяния кожи человека. Значения коэффициентов

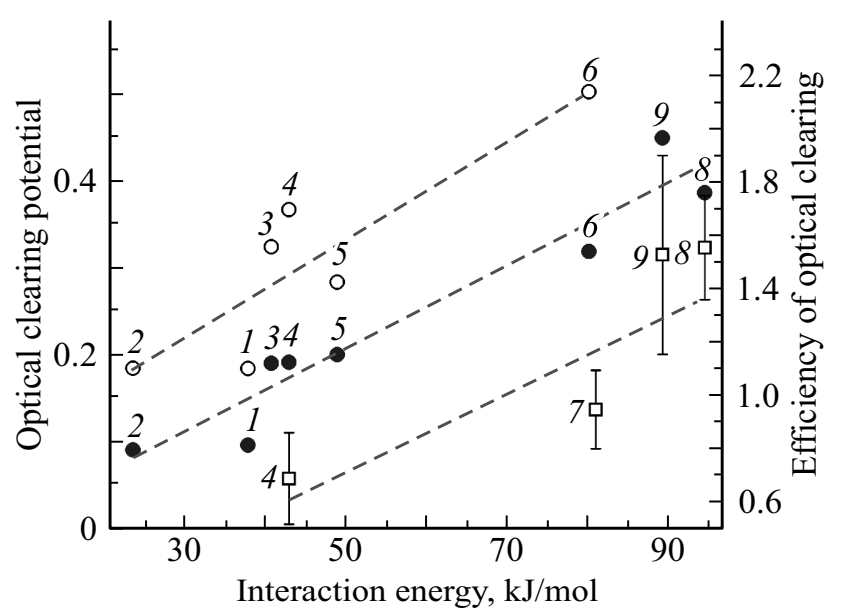

Рис. 4. Потенциалы оптического просветления (левая ось ординат) кожи крысы (черные кружки) и человека (светлые кружки) [1], а также эффективность оптического просветления кожи человека (квадраты, правая ось ординат) в зависимости от энергии взаимодействия молекулы пептида коллагена с молекулами просветляющих агентов. Штриховыми линиями обозначены линейные аппроксимации этих зависимостей. Цифрами на графиках обозначены иммерсионные агенты: 1 этиленгликоль; 2 - 1,2-пропандиол; 3 - 1,3-пропандиол; 4 глицерол; 5 - ксилитол; $6-$ сорбитол; 7 - рибоза; $8-$ глюкоза; $9-$ фруктоза.

линейной корреляции составляют соответственно 0.94 и 0.88. Это позволяет говорить о принципиальной важности последиффузионного этапа, в котором происходит взаимодействие коллагена с просветляющими агентами и осуществляется его влияние на оптическое просветление биотканей. Результаты исследования позволяют говорить о том, что в процессе такого взаимодействия происходит частичное замещение связанной с коллагеном воды. Это приводит к нарушению связующей сетки водородных связей и, как следствие, к обратимому процессу растворения коллагеновых фибрилл, что в свою очередь уменьшает их показатель преломления и выравнивает его с межколлагеновой средой. Чем выше сродство просветляющего агента к коллагену, тем эффективнее идет этот процесс.

Следующим принципиальным шагом для увеличения эффективности взаимодействия может быть подбор молекулярного агента с такими структурными характеристиками, которые позволяли бы ему взаимодействовать сразу с двумя или более молекулярными карманами коллагена. Таким эффективным просветляющим агентом может служить молекулярная система полимерного типа, состоящая, например, из шестичленных моносахаридов, соединенных подвижной углеродно- кислородной цепочкой такой длины, чтобы насыщенные кольца сахара попадали в области молекулярных карманов коллагена и взаимодействовали с ними посредством своих гидроксильных групп. Следует заметить, что значительное увеличение размера молекул, используемых в качестве про- 
светляющих агентов, приведет к увеличению вязкости вещества и как следствие к уменьшению коэффициента диффузии его в биоткани, а также к увеличению времени его вымывания из биотканей.

\section{Благодарности}

Авторы выражают благодарность Э.А. Гениной, А.Н. Башкатову и Д.К. Тучиной за помощь в проведении экспериментов.

\section{Финансирование работы}

Работа была частично поддержана грантами РФФИ: № 18-52-16025 НЦНИЛ_а, 18-07-01228 а; при финансовой поддержке в рамках государственных заданий высшим учебным заведениям и научным организациям в сфере научной деятельности, полученных от Министерства образования и науки РФ (рег. номер: 3.9128.2017/БЧ).

\section{Конфликт интересов}

Авторы заявляют, что у них нет конфликта интересов.

\section{Список литературы}

[1] Hirshburg J.M. Chemical agent induced reduction of skin light scattering: doctoral dissertation. Texas A\&M University, 2009. P. 119.

[2] Tuchin V.V. // Handbook of Optical Sensing of Glucose in Biological Fluids and Tissues. Taylor \& Francis Group LLC, CRC Press, 2009. P. 744.

[3] Tuchin V.V. // Optical Clearing of Tissues and Blood. PM 154, Bellingham, WA: SPIE Press, 2006. P. 256.

[4] Zhu D., Larin K.V., Luo Q., Tuchin V.V. // Laser Photonics Rev. 2013. V. 7. N 5. P. 732. doi 10.1002/lpor.201200056

[5] Genina E.A., Bashkatov A.N., Sinichkin Yu.P., Yanina I.Yu., Tuchin V.V. // J. Biomed. Photon. Eng. 2015. V. 1. N 1. P. 22. doi $10.18287 /$ jbpe-2015-1-1-22

[6] Генина Э.А., Башкатов А.Н., Кочубей В.И., Тучин В.В. // Опт. и спектр. 2005. Т. 98. № 3. С. 515; Genina E.A., Bashkatov A.N., Kochubey V.I., Tuchin V.V. // Opt. Spectrosc. 2005. V. 98. N 3. P. 470. doi 10.1134/1.1890530

[7] Генина Э.А., Башкатов А.Н., Синичкин Ю.П., Тучин В.В. // Квантовая электроника. 2006. Т. 36. № 12. C. 1119; Genina E.A., Bashkatov A.N., Sinichkin Yu.P., Tuchin V.V. // Quantum Electronics. 2006. V. 36. N 12. P. 1119. doi 10.1070/QE2006v036n12ABEH013337

[8] Bashkatov A.N., Korolevich A.N., Tuchin V.V., Sinichkin Yu.P., Genina E.A., Stolnitz M.M., Dubina N.S., Vecherinski S.I., Belsley M.S. // Asian J. Phys. 2006. V. 15. N 1. P. 1.

[9] Genina E.A., Bashkatov A.N., Tuchin V.V. // Adv. Optical Technologies. 2008. V. 2008. Article ID 267867. doi 10.1155/2008/267867

[10] Bashkatov A.N., Genina E.A., Tuchin V.V., Altshuler G.B. // Laser Physics. 2009. V. 19. N 6. P. 1312. doi 10.1134/S1054660X09060231

[11] Wen X., Tuchin V.V., Luo Q., Zhu D. // Phys. Med. Biol. 2009. V. 54. N 22. P. 6917. doi 10.1088/0031-9155/54/22/011
[12] Sudheendran N., Larin K.V., Mohamed M., Ghosn M.G., Tuchin V.V. // J. Innovative Optical Health Sciences. 2010. V. 3. N 3. P. 169. doi 10.1142/S1793545810001039

[13] Wen X., Jacques S.L., Tuchin V.V., Zhu D. // J. Biomed. Opt. 2012. V. 17. N 6. P. 066022. doi 10.1117/1.JBO.17.6.066022

[14] Simonenko G.V., Kirillova E.S., Tuchin V.V. // Optical Memory \& Neural Networks. 2009. V. 18. N 2. P. 129. doi 10.3103/S1060992X09020106

[15] Ларин К.В., Тучин В.В. // Квантовая электроника. 2008. T. 38. № 6. C. 551; Larin K.V., Tuchin V.V. // Quantum Electronics. 2008. V. 38. N 6. P. 551-556. doi 10.1070/QE2008v038n06ABEH013850

[16] Tuchina D.K., Shi R., Bashkatov A.N., Genina E.A., Zhu D., Luo Q., Tuchin V.V. // J. Biophotonics. 2015. V. 8. N 4. P. 332. doi 10.1002/jbio.201400138

[17] Wen X., Mao Z., Han Z., Tuchin V.V., Zhu D. // J. Biophotonics. 2010. V. 3. N 1-2. P. 44. doi 10.1002/jbio.200910080

[18] Hirshburg J.M., Ravikumar K.M., Hwang W., Yeh A. // J. Biomed. Opt. 2010. V. 15. N 5. P. 055002. doi $10.1117 / 1.3484748$

[19] Feng W., Shi R., Ma N., Tuchina D.K., Tuchin V.V., Zhu D. // J. Biomed. Opt. 2016. V. 21. N 8. P. 081207. doi 10.1117/1.JBO.21.8.081207

[20] Yu T., Wen X., Tuchin V.V., Luo Q., Zhu D. // J. Biomed. Opt. 2011. V. 16. N 9. P. 095002. doi $10.1117 / 1.3621515$

[21] Dvoretsky K.N., Berezin K.V., Chernavina M.L., Likhter A.M., Shagautdinova I.T., Antonova E.M., Rybakov A.V., Grechukhina O.N., Tuchin V.V. // Proc. SPIE. 2018. V. 10716. P. 1071624. doi 10.1117/12.2311866

[22] Dvoretsky K.N, Berezin K.V., Chernavina M.L., Likhter A.M., Shagautdinova I.T., Antonova E.M., Grechukhina O.N., Tuchin V.V. // J. Surface Investigation. 2018. V. 12. N 5. P. 961. doi 10.1134/S1027451018050233

[23] Berezin K.V., Dvoretski K.N., Chernavina M.L., Likhter A.M., Smirnov V.V., Shagautdinova I.T., Antonova E.M., Stepanovich E.Yu., Dzhalmuhambetova E.A., Tuchin V.V. // J. Mol. Modeling. 2018. V. 24. N 2. P. 45. doi 10.1007/s00894-0183584-0

[24] Berezin K.V., Dvoretskiy K.N., Chernavina M.L., Nechaev V.V., Likhter A.M., Shagautdinova I.T., Stepanovich E.Yu., Grechukhina O.N., Tuchin V.V. // Proc. SPIE. 2017. V. 10336. P. 103360J. doi 10.1117/12.2267979

[25] Bashkatov A.N., Berezin K.V., Dvoretskiy K.N., Chernavina M.L., Genina E.A., Genin V.D., Kochubey V.I., Lazareva E.N., Pravdin A.B., Shvachkina M.E., Timoshina P.A., Tuchina D.K., Yakovlev D.D., Yakovlev D.A., Yanina I.Yu., Zhernovaya O.S., Tuchin V.V. // J. Biomed. Opt. 2018. V. 23. N 9. P. 091416. doi 10.1117/1.JBO.23.9.091416

[26] Faber D.J., van der Meer F.J., Aalders M.C.G., van Leeuwen T.G. // Opt. Express. 2004. V. 12. N 19. P. 4353. doi 10.1364/OPEX.12.004353

[27] Lee P., Gao W., Zhang X. // Appl. Opt. 2010. V. 49. N 18. P. 3538. doi 10.1364/AO.49.003538

[28] Genina E.A., Bashkatov A.N., Kolesnikova E.A., Basko M.V., Terentyuk G.S., Tuchin V.V. // J. Biomed. Opt. V. 19. N 2. P. 021109. doi 10.1117/1.JBO.19.2.021109

[29] Wang R.K., Tuchin V.V. // Handbook of Coherent-Domain Optical Methods. Biomedical Diagnostics, Environmental Monitoring, and Material Science. Springer. 2013. V. 2. P. 665.

[30] Okuyama K., Miyama K., Mizuno K., Bachinger H.P. // Biopolymers. 2012. V. 97. N 8. P. 607. doi 10.1002/bip.22048 
[31] Cornell W.D., Cieplak P., Bayly C.I., Gould I.R., Merz K.M. Jr., Ferguson D.M., Spellmeyer D.C., Fox T., Caldwell J.W., Kollman P.A. // J. Am. Chem. Soc. 1995. V. 117. N 19. P. 5179. doi 10.1021/ja00124a002

[32] Becke A.D. // J. Chem. Phys. 1993. V. 98. N 7. P. 5648. doi $10.1063 / 1.464913$

[33] Lee C., Yang W., Parr R.G. // Phys. Rev B. 1988. V. 37. N 2. P. 785. doi 10.1103/PhysRevB.37.785

[34] Frisch M.J., Trucks G.W., Schlegel H.B. et al. Gaussian09, Revision A.02. Pittsburgh PA: Gaussian, Inc. 2009.

[35] van der Spoel D., Lindahl E., Hess B., Groenhof G., Mark E.A., Berendsen H.J.C. // J. Comput. Chem. 2005. V. 26. N 16. P. 1701. doi 10.1002/jcc.20291

[36] Duan Y., Wu C., Chowdhury S., Lee M.C., Xiong G., Zhang W., Yang R., Cieplak P., Luo R., Lee T., Caldwell J., Wang J., Kollman P. // J. Comp. Chem. 2003. V. 24. N 16. P. 1999. doi 10.1002/jcc.10349 